\title{
Validade comercial de filés de Tilápia do Nilo (Oreochromis niloticus) resfriados embala- dos em atmosfera modificada e irradiados
}

\author{
Shelf life of refrigerated tilapia fillets (Oreochromis niloticus) packed in modified atmosphere and \\ irradiated
}

\author{
Maria Lúcia Guerra Monteiro ${ }^{\mathrm{I}}$ Eliane Teixeira Mársico ${ }^{\mathrm{II}}$ Claudia Emília Teixeira ${ }^{\mathrm{II}}$ \\ Sérgio Borges ManoII Carlos Adam Conte Júnior ${ }^{\text {II }}$ Helio de Carvalho Vital ${ }^{\text {II }}$
}

\section{RESUMO}

O objetivo do presente estudo foi avaliar os efeitos dos processos de irradiação (com dose de 1,5kGy) e embalagem em atmosfera modificada (60\% $\mathrm{N}_{2}$ e $\left.40 \% \mathrm{CO}_{2}\right)$, aplicados isoladamente ou combinados, na extensão da validade comercial de filés de Tilápia do Nilo (Oreochromis niloticus) resfriados. Nos experimentos, foram utilizados 120 filés separados em lotes, de acordo com o tratamento: (T1) embalagem em ar (controle), (T2) embalagem em atmosfera modificada, (T3) embalagem em ar e irradiação, (T4) embalagem em atmosfera modificada e irradiação. Foram realizadas análises físico-químicas (BVT, TMA, pH, amônia e TBARS), bacteriológicas (contagem de bactérias heterotróficas, aeróbias, mesófilas e psicrotróficas) e avaliação sensorial. Os resultados consistentemente indicaram uma redução progressiva da qualidade do produto com o tempo de armazenamento, a qual foi significativamente mais rápida nas amostras controle do que naquelas submetidas aos demais tratamentos, tendo sido observada uma extensão na validade comercial dos filés embalados em atmosfera modificada e/ou irradiados de 4 dias para aproximadamente duas semanas.

Palavras-chave: pescado, peixe dulcícola, métodos de conservação, radiação gama, césio-137.

\section{ABSTRACT}

This paper investigated the effects of modified atmosphere packing $\left(60 \% \mathrm{~N}_{2}\right.$ and $\left.40 \% \mathrm{CO}_{2}\right)$ and irradiation (with a 1.5kGy dose) either used alone or combined on the shelf life of fillets of refrigerated Nile Tilapia. A total of 120 fillets were used in the experiments in order to test four different treatments and included samples: packed in air (control), packed in modified atmosphere, packed in air and irradiated, and finally, packed in modified atmosphere and irradiated. Regular monitoring of physicochemical parameters (TVB, $\mathrm{pH}$, ammonia and TBARS), bacteriological conditions (heterotrophic aerobic mesophilic and psychrotrophic bacteria) and sensory acceptance were performed. The results consistently indicated an increasing deterioration of the fillets with time, however those treated with irradiation, modified atmosphere or both combined had longer shelf lives (around two weeks) in comparison with the control (4 days only).

Key words: fish, fresh water fish, conservation methods, gamma radiation, cesium- 137 .

\section{INTRODUÇÃO}

A tilápia (Oreochromis niloticus) é, atualmente, a espécie mais produzida no Brasil, devido às suas características reprodutivas, genéticas e, principalmente, mercadológicas, sendo encontrada em praticamente todo o território nacional. Em 2009, representou 39\% do total de pescado proveniente da piscicultura continental, totalizando 132,957 toneladas (BRASIL, 2010), sendo o filé a preferência nacional de consumo da carne desta espécie. Além disso, trata-se de peixe que apresenta elevado valor nutritivo, constituído por proteínas de alto valor biológico, aminoácidos essenciais e ácidos graxos, especialmente da série ômega-3, os quais são benéficos à saúde

\footnotetext{
IPrograma de Pós-graduação em Higiene Veterinária e Processamento Tecnológico de Produtos de Origem Animal (POA), Faculdade de Veterinária, Universidade Federal Fluminense (UFF), Niterói, RJ, Brasil. E-mail: marialuciaguerra@yahoo.com.br. Autor para correspondência.

IIDepartamento de Tecnologia de Alimentos, Faculdade de Veterinária, UFF, Niterói, RJ, Brasil.

IIICentro Tecnológico do Exército (CTEx), Guaratiba, RJ, Brasil.
} 
humana. Entretanto, dentre os produtos de origem animal, o pescado é uma das matrizes alimentares mais susceptíveis ao processo de deterioração (MÁRSICO et al., 2006).

O filé de Tilápia do Nilo (Oreochromis niloticus) é encontrado no comércio varejista como mais uma opção para o consumidor, que se encontra atento a questões relacionadas ao consumo de alimentos nutritivos e frescos e também à garantia da segurança microbiológica, físico-química e sensorial. Todavia, no processo de filetagem é onde ocorre maior contaminação bacteriana, sendo considerado um ponto crítico de controle durante o beneficiamento de tilápia (CARBONERA et al., 2011). Justifica-se, portanto, a pesquisa de tecnologias modernas de conservação, inclusive o emprego simultâneo de dois ou mais processos, que assegurem tais atributos, além de aumentar a validade comercial do produto.

A embalagem em atmosfera modificada (EAM) tem o potencial de retardar o crescimento microbiano, devido à dissolução do $\mathrm{CO}_{2}$ em água formando o ácido carbônico, reduzindo, dessa maneira, o pH e, consequentemente, estendendo a validade comercial dos alimentos (MANO et al., 2000), além de propiciar o transporte a mercados distantes, incrementando o valor comercial dos produtos e reduzindo custos.

A irradiação vem se destacando por possuir grande eficácia na redução da carga microbiana, decorrente do efeito da radiação ionizante sobre o DNA cromossômico, lesando os ácidos nucléicos das bactérias contaminantes, acarretando a morte celular, o que geralmente contribui para o aumento da validade comercial (VITAL \& FREIRE, 2008), sem produzir alterações significativas nas características sensoriais e nutricionais dos produtos.

Considerando os aspectos supracitados, o presente estudo objetivou avaliar o efeito, isolado e combinado, da embalagem com atmosfera modificada e da irradiação na extensão da validade comercial de filés de Tilápia do Nilo (Oreochromis niloticus) resfriados.

\section{MATERIAL E MÉTODOS}

Os filés de tilápia foram obtidos numa Empresa localizada em Piraí, Rio de Janeiro, e foram separados em quatro lotes, de acordo com o tratamento: 15 filés de tilápia para T1 (controle), 30 para T2 (embalagem em atmosfera modificada com $40 \% \mathrm{CO}_{2}$ e $60 \% \mathrm{~N}_{2}$ ), 30 para T3 (irradiação com dose de 1,5kGy) e 45 para T4 (EAM e irradiação, utilizando as mesmas condições do T2 e T3), totalizando 120 unidades amostrais.
O processo de EAM foi realizado sob condições laboratoriais e a irradiação, com fonte césio137, no Centro Tecnológico do Exército (CTEx), Guaratiba/RJ, utilizando-se gelo seco durante o processo. A escolha da concentração de gases e a dose de radiação gama basearam-se em trabalhos anteriores, como o de TEIXEIRA (2009). As amostras foram transportadas em caixas isotérmicas com gelo reciclável $\left(0 \pm 1^{\circ} \mathrm{C}\right)$ e periodicamente submetidas às análises físicoquímicas, bacteriológicas e sensoriais nos respectivos laboratórios da UFF. Vale ressaltar que não houve determinação prévia de intervalo de tempo, isto é, a periodicidade da realização das análises foi estabelecida com base na evolução dos resultados de cada procedimento.

As análises físico-químicas incluíram a determinação de Bases Voláteis Totais - BVT (mg NBVT $100 g^{-1}$ de amostra), trimetilamina - TMA (mg NTMA $100 \mathrm{~g}^{-1}$ de amostra), amônia, $\mathrm{pH}$ e ranço oxidativo pelo número de substâncias reativas ao ácido 2tiobarbitúrico - TBARS (mg de malonaldeído $\mathrm{kg}^{-1} \mathrm{de}$ amostra), seguindo as especificações preconizados pelo Laboratório Nacional de Referência Animal (BRASÍLIA, 1981). A determinação do ranço oxidativo foi adaptada segundo as propostas de TARLADGIS et al. (1960). As análises bacteriológicas incluíram a contagem de bactérias heterotróficas, aeróbias, mesófilas (BRASÍLIA, 2003) e psicrotróficas (APHA, 2001).

A avaliação sensorial foi realizada a partir do teste de aceitação com uso da escala hedônica de nove pontos ( 9 - gostei extremamente; 1 - desgostei extremamente), por um grupo de 30 julgadores não treinados que avaliaram os atributos “cor” e "aparência geral”.

O tratamento estatístico dos resultados físico-químicos foi realizado através da análise de regressão polinomial de $2^{\circ}$ grau, exceto os valores da análise de TBARS que foi tratado estatisticamente por regressão polinomial de $3^{\circ}$ grau. Nos resultados bacteriológicos foi aplicada regressão linear através do método de Baranyi. Na avaliação sensorial, foram calculadas as médias e os desvios-padrão associados aos julgamentos dos diferentes atributos e tratamentos, que foram tratados estatisticamente por análise de variância e posterior teste de Tukey ao nível de 5\% de significância, sendo que graus médios correspondentes ao termo hedônico igual a 5 (nem gostei/nem desgostei) foram considerados indicativos de rejeição.

\section{RESULTADOS E DISCUSSÃO}

Os resultados de BVT, TMA, pH e amônia exibiram tendência crescente ao longo do período de 
estocagem em todos os tratamentos, indicando, como esperado, uma redução na qualidade das amostras com o tempo. No entanto, os valores obtidos para os grupos T2, T3 e T4 cresceram mais lentamente, indicando deterioração mais lenta na qualidade do produto, a qual manteve-se superior àquela do controle, como pode ser observado nas tabelas 1 e 2 .

Os valores iniciais de $\mathrm{N}-\mathrm{BVT}$ e $\mathrm{pH}$ nas amostras submetidas aos tratamentos 1 , 2, 3 e 4 foram 7,56; 9,45; 5,04; 5,04mg N-BVT 100g ${ }^{-1}$ e 6,35; 6,33; 6,21 e 6,20, respectivamente. A legislação nacional estabelece o limite de 30mg N-BVT $100 \mathrm{~g}^{-1}$ de amostra e determina que o $\mathrm{pH}$ da carne externa do pescado deva ser inferior a 6,8 e o pH da carne interna inferior a 6,5 (BRASÍLIA, 2008). Os valores dos filés controle alcançaram tais limites no $6^{\circ}$ (30,87mg N-BVT $\left.100 \mathrm{~g}^{-1}\right)$ e $5^{\circ}$ dia $(6,90)$, enquanto os resultados das amostras submetidas aos tratamentos 2, 3 e 4 atingiram o preconizado para BVT nos dias 13(31,5), 15(30,87), 18(30,87mg N-BVT 100g-1) e para $\mathrm{pH}$ nos dias $12(6,81), 13(6,80)$ e $20(6,84)$, respectivamente. É importante salientar que os valores de BVT desta e de outras espécies, incluindo as marinhas, devem ser criteriosamente revisados em função do teor inicial de óxido de trimetilamina de cada espécie e os valores de $\mathrm{pH}$ podem variar de forma significativa em função do processo de despesca ou captura do pescado, sugerindo estabelecimento de valores para cada situação.

Com relação à determinação de TMA no dia zero, observou-se 1,26mg N-TMA $100 \mathrm{~g}^{-1}$ independente do tratamento aplicado. Os valores para as amostras controle ultrapassaram o limite, 4mg N-TMA $100 \mathrm{~g}^{-1}$ de amostra (BRASÍLIA, 2008), no 5ํㅡㄹ dia (41,4mg N-TMA $\left.100 \mathrm{~g}^{-1}\right)$, enquanto aqueles associados aos tratamentos 2 , 3 e 4 atingiram esse limite no $13^{\circ}(4,41), 13^{\circ}(4,41)$ e 17ํㅡㄹ dia (4,41mg N-TMA $\left.100 \mathrm{~g}^{-1}\right)$ de estocagem sob refrigeração, respectivamente.

A reação de amônia foi negativa até o dia 2 nas amostras controle, tornando-se levemente positiva no $3^{\circ}$ dia, positiva no $4^{\circ}$ e $5^{\circ}$ dias e fortemente positiva no $6^{\circ}$ dia de estocagem em gelo reciclável. As amostras do lote T2 apresentaram resultado negativo até o $11^{\circ}$ dia de armazenagem, tornando-se positiva do $12^{\circ}$ ao 14ํㅡㄹ. Nias amostras do grupo T3, a reação foi

Tabela 1 - Resultados das análises de Bases Voláteis Totais (BVT) (expresso em mg de N-BVT/100g de amostra) e Trimetilamina (TMA) (expresso em mg de TMA/100g de amostra) em filés de tilápia (Oreochromis niloticus) estocados em gelo reciclável durante 20 dias.

\begin{tabular}{|c|c|c|c|c|c|c|c|c|}
\hline \multirow[b]{2}{*}{ Dias } & \multicolumn{2}{|c|}{--------------T1-------------- } & \multicolumn{2}{|c|}{------------T2------------- } & \multicolumn{2}{|c|}{ 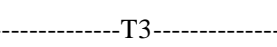 } & \multicolumn{2}{|c|}{ 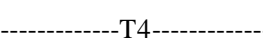 } \\
\hline & BVT & TMA & BVT & TMA & BVT & TMA & BVT & TMA \\
\hline 0 & 7,56 & 1,26 & 9,45 & 1,26 & 5,04 & 1,26 & 5,04 & 1,26 \\
\hline 1 & 8,82 & 1,26 & $\mathrm{NR}^{*}$ & $\mathrm{NR}^{*}$ & $\mathrm{NR}^{*}$ & $\mathrm{NR}^{*}$ & $\mathrm{NR}^{*}$ & $\mathrm{NR}^{*}$ \\
\hline 2 & 11,34 & 1,26 & 10,08 & 1,26 & 6,93 & 1,26 & 6,3 & 1,26 \\
\hline 3 & 17,64 & 2,52 & $\mathrm{NR}^{*}$ & $\mathrm{NR}^{*}$ & $\mathrm{NR}^{*}$ & $\mathrm{NR}^{*}$ & $\mathrm{NR}^{*}$ & $\mathrm{NR}^{*}$ \\
\hline 4 & 26,46 & 3,15 & $\mathrm{NR}^{*}$ & $\mathrm{NR}^{*}$ & $\mathrm{NR}^{*}$ & $\mathrm{NR}^{*}$ & $\mathrm{NR}^{*}$ & $\mathrm{NR}^{*}$ \\
\hline 5 & 27,72 & 4,41 & $\mathrm{NR}^{*}$ & $\mathrm{NR}^{*}$ & $\mathrm{NR}^{*}$ & $\mathrm{NR}^{*}$ & $\mathrm{NR}^{*}$ & $\mathrm{NR}^{*}$ \\
\hline 6 & 30,87 & 5,67 & $\mathrm{NR}^{*}$ & NR* & $\mathrm{NR}^{*}$ & $\mathrm{NR}^{*}$ & NR* & $\mathrm{NR}^{*}$ \\
\hline 7 & 30,39 & 6,93 & 18,9 & 1,26 & 11,34 & 1,26 & 8,19 & 1,26 \\
\hline 9 & NR & NR & 20,16 & 2,52 & 16,38 & 2,52 & 9,45 & 1,89 \\
\hline 11 & NR & NR & 26,96 & 3,78 & 20,79 & 2,52 & 11,34 & 2,52 \\
\hline 12 & NR & NR & 29,61 & 3,78 & 25,2 & 3,15 & 16,38 & 2,52 \\
\hline 13 & NR & NR & 31,5 & 4,41 & 27,72 & 4,41 & 17,64 & 3,15 \\
\hline 14 & NR & NR & 32,76 & 5,04 & 29,61 & 5,04 & 21,42 & 3,15 \\
\hline 15 & NR & NR & 32,76 & 5,67 & 30,87 & 5,67 & 23,94 & 3,78 \\
\hline 16 & NR & NR & 44,73 & 5,67 & 32,13 & 6,3 & 25,83 & 3,78 \\
\hline 17 & NR & NR & 34,65 & 6,3 & 32,76 & 6,93 & 29,61 & 4,41 \\
\hline 18 & NR & NR & 33,39 & 6,3 & 34,65 & 6,93 & 30,87 & 5,04 \\
\hline 19 & NR & NR & NR & NR & NR & NR & 31,5 & 6,93 \\
\hline 20 & NR & NR & NR & NR & NR & NR & 33,39 & 6,3 \\
\hline
\end{tabular}

Em que: T1 = embalagem em aerobiose (controle), T2 = embalagem em atmosfera modificada ( $40 \% \mathrm{CO}_{2}$ e $60 \%$ N N $_{2}$, T3 (irradiação na dose de 1,5kGy) e T4 = embalagem em atmosfera e irradiação (nas mesmas condições de T2 e T3). NR: Não realizado devido ao fato de os resultados já apresentarem valores acima do limite estabelecido pela legislação nacional. NR*: Não realizado devido aos resultados anteriores. 
Tabela 2 - Resultados das análises de pH e número de substâncias reativas ao ácido 2-tiobarbitúrico (TBARS) (expresso em mg de malonaldeído $\mathrm{kg}^{-1}$ de amostra), em filés de tilápia (Oreochromis niloticus) estocados em gelo reciclável durante 20 dias.

\begin{tabular}{|c|c|c|c|c|c|c|c|c|}
\hline \multirow{2}{*}{ Dias } & \multicolumn{2}{|c|}{-------------T1--------------. } & \multicolumn{2}{|c|}{ 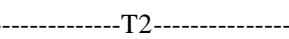 } & \multicolumn{2}{|c|}{-------------T3-------------.- } & \multicolumn{2}{|c|}{-------------T4------------. } \\
\hline & $\mathrm{pH}$ & TBARS & $\mathrm{pH}$ & TBARS & $\mathrm{pH}$ & TBARS & $\mathrm{pH}$ & TBARS \\
\hline 0 & 6,35 & 0,47 & 6,33 & 0,79 & 6,21 & 1,43 & 6,20 & 1,27 \\
\hline 1 & 6,36 & 0,47 & $\mathrm{NR}^{*}$ & $\mathrm{NR}^{*}$ & $\mathrm{NR}^{*}$ & $\mathrm{NR}^{*}$ & $\mathrm{NR}^{*}$ & $\mathrm{NR}^{*}$ \\
\hline 2 & 6,37 & 0,95 & 6,34 & 0,95 & 6,22 & 1,9 & 6,28 & 1,58 \\
\hline 3 & 6,48 & 0,95 & $\mathrm{NR}^{*}$ & $\mathrm{NR}^{*}$ & $\mathrm{NR}^{*}$ & $\mathrm{NR}^{*}$ & NR* & $\mathrm{NR}^{*}$ \\
\hline 4 & 6,55 & 1,27 & $\mathrm{NR}^{*}$ & $\mathrm{NR}^{*}$ & $\mathrm{NR}^{*}$ & $\mathrm{NR}^{*}$ & $\mathrm{NR}^{*}$ & $\mathrm{NR}^{*}$ \\
\hline 5 & 6,90 & 1,43 & $\mathrm{NR}^{*}$ & NR* & $\mathrm{NR}^{*}$ & $\mathrm{NR}^{*}$ & $\mathrm{NR}^{*}$ & NR* \\
\hline 6 & 6,90 & 1,58 & $\mathrm{NR}^{*}$ & $\mathrm{NR}^{*}$ & $\mathrm{NR}^{*}$ & $\mathrm{NR}^{*}$ & $\mathrm{NR}^{*}$ & $\mathrm{NR}^{*}$ \\
\hline 7 & 6,92 & 2,69 & 6,37 & 1,27 & 6,26 & 2,22 & 6,30 & 1,9 \\
\hline 9 & NR & NR & 6,51 & 1,43 & 6,37 & 2,22 & 6,40 & 2,06 \\
\hline 11 & NR & NR & 6,76 & 1,58 & 6,62 & 3,64 & 6,44 & 2,53 \\
\hline 12 & NR & NR & 6,81 & 1,74 & 6,73 & 4,59 & 6,52 & 3,17 \\
\hline 13 & NR & NR & 6,86 & 2,06 & 6,80 & 5,07 & 6,59 & 3,64 \\
\hline 14 & NR & NR & 6,89 & 3,8 & 6,81 & 3,33 & 6,59 & 3,8 \\
\hline 15 & NR & NR & 6,91 & 3,17 & 6,85 & 2,06 & 6,60 & 4,75 \\
\hline 16 & NR & NR & 6,93 & 2,38 & 6,91 & 1,58 & 6,69 & 2,06 \\
\hline 17 & NR & NR & 6,93 & 1,74 & 6,97 & 1,27 & 6,70 & 1,9 \\
\hline 18 & NR & NR & 6,96 & 1,58 & 6,97 & 0,95 & 6,73 & 1,58 \\
\hline 19 & NR & NR & NR & NR & NR & NR & 6,75 & 1,27 \\
\hline 20 & NR & NR & NR & NR & NR & NR & 6,84 & 1,27 \\
\hline
\end{tabular}

Em que: T1 = embalagem em aerobiose (controle), T2 = embalagem em atmosfera modificada (40\% CO $\mathrm{CO}_{2} 60 \%$ N ), T3 (irradiação na dose de 1,5kGy) e T4 = embalagem em atmosfera e irradiação (nas mesmas condições de T2 e T3). NR: Não realizado devido ao fato de os resultados já apresentarem valores acima do limite estabelecido pela legislação nacional. NR*: Não realizado devido aos resultados anteriores.

levemente positiva nos dias $12^{\circ}$ e $13^{\circ}$, enquanto, nas do lote $\mathrm{T} 4$, o mesmo ocorreu do $12^{\circ}$ dia ao $16^{\circ}$. A reação das amostras submetidas ao tratamento 2 , 3 e 4 apresentou-se fortemente positiva a partir do dia 15, 16 e 18, respectivamente. É curioso observar que apesar de ser um procedimento qualitativo, sugere resultados mais coerentes em função da desaminação ocorrida tanto nos aminoácidos como degradação de nucleotídeos.

As Bases Voláteis Totais (BVT) incluem, dentre outros, a Trimetilamina (TMA) e amônia, compostos produzidos durante a deterioração alteram o $\mathrm{pH}$ do pescado, visto que a atividade enzimática e a ação bacteriana alteram a concentração de íons de hidrogênio livre (OGAWA \& MAIA,1999). A EAM reduz a produção de BVT devido ao efeito bacteriostático sobre a microbiota (TEIXEIRA, 2009) e o processo de irradiação reduz a carga microbiana diminuindo a decomposição do óxido de trimetilamina, mas fundamentalmente inibindo a produção de amônia oriunda da degradação de aminoácidos. Ou seja, a irradiação e a EAM reduzem os valores de $\mathrm{pH}$ e a produção de BVT, TMA e amônia durante a deterioração do pescado e a combinação desses métodos potencializa a manutenção da qualidade deste, devido ao efeito sinérgico de ambos os processos, fato confirmado neste estudo.

TEIXEIRA (2009) relatou que os valores de BVT e pH de filés de tilápia controle mantidos sob refrigeração aumentaram rapidamente quando comparados àqueles dos filés somente tratados com EAM ( $40 \% \mathrm{CO}_{2}$ e $60 \% \mathrm{~N}_{2}$ ), irradiados (1,5kGy) e embalados e irradiados que, apesar de crescentes, mantiveram-se menores durante o período de estocagem, resultados que corroboram os dados do presente estudo, provavelmente, devido ao efeito eficaz da EAM, irradiação e combinação de ambos os métodos na redução bacteriana.

Quanto aos resultados de TBARS nas amostras controle (Tabela 2), observou-se aumento ao longo do período de estocagem com uma variação de 0,47 a 2,69mg de malonaldeído $\mathrm{kg}^{-1}$, do primeiro ao sétimo dia de estocagem, quando as amostras já apresentavam características sensoriais inaceitáveis. Como não há padrão para este parâmetro na legislação nacional, os resultados são comparados com achados de trabalhos anteriores descritos na literatura. ALKAHTANI et al. (1996) afirmaram que peixes, como 
tilápia e cavalinha, podem ser considerados em bom estado de conservação apresentando valores abaixo de 3,0mg de malonaldeído $\mathrm{kg}^{-1}$ de amostra, o que pode sugerir que o ranço não tenha sido considerado um parâmetro de perda de qualidade em amostras submetidas à refrigeração.

Entretanto, os valores iniciais das amostras dos lotes T2, T3 e T4 foram 0,79; 1,43 e 1,27mg de malonaldeído $\mathrm{kg}^{-1}$, respectivamente, ou seja, maiores quando comparados com o do controle. Os valores observados nas amostras tratadas com EAM corroboram os achados de MASNIYOM et al. (2002), que constataram aumento proporcional à concentração de $\mathrm{CO}_{2}$, provavelmente, devido à dissolução desse gás no músculo, ocasionando alteração da permeabilidade das membranas celulares interferindo no potencial antioxidante. Os valores nas amostras irradiadas foram maiores que nas demais, provavelmente devido à formação de radicais livres que ocorre durante a irradiação e pode ocasionar o ranço. Em contrapartida, os resultados observados nas amostras do grupo T4 apresentaram-se inferiores aos das amostras dos grupos T2 e T3, pois as alterações indesejadas resultantes da irradiação (rancificação oxidativa) podem ser reduzidas com a exclusão do oxigênio (VITAL \& FREIRE, 2008).

Os valores máximos encontrados nas amostras dos grupos T2, T3 e T4 foram 3,8; 5,07 e 4,75mg de malonaldeído $\mathrm{kg}^{-1}$ nos dias 14,13 e 15, respectivamente. Entretanto, esses valores decresceram continuamente (1,58; 2,06 e 1,27mg de malonaldeído $\mathrm{kg}^{-1}$ ) até apresentarem aspectos sensoriais e bacteriológicos característicos de um produto impróprio para o consumo. AL-KAHTANI et al. (1996) relataram uma possível interação covalente do malonaldeído com os grupos aminas livres presentes nas proteínas.

Em relação aos resultados bacteriológicos, como a legislação brasileira não prevê limites para contagem em placas de bactérias aeróbias, mesófilas e psicrotróficas para filés de pescado, foi estabelecido o limite de 8Log UFC g ${ }^{-1}$ neste estudo, baseando-se na literatura (FRANCO \& LANDGRAF (1996), visto que, somente quando a contagem das amostras ultrapassou tal valor, os filés passaram a ser rejeitados na avaliação sensorial.

A contagem de bactérias heterotróficas, aeróbias, mesófilas e psicrotróficas (Figura 1) nas amostras controle foram realizadas em menor intervalo de tempo (horas), devido ao rápido crescimento bacteriano nessas amostras. Após 3 horas da coleta dos filés, a carga microbiana do grupo $\mathrm{T} 1$ foi de 4,2Log UFC $\mathrm{g}^{-1}$ para mesófilos, sem crescimento de psicrotróficos. A partir dessa hora, até 43 horas e meia da coleta, a população de mesófilos permaneceu em torno de 4,3Log UFC g$^{-1}$, não tendo havido detecção de psicrotróficos. Após 45 horas e meia da coleta, iniciou-se o crescimento bacteriano, tanto de mesófilos $(5,5)$ como de psicrotróficos $\left(4,0 \log \mathrm{UFC} \mathrm{g}^{-1}\right)$, que foi caracterizado por um aumento progressivo. Após 95 horas e meia da coleta (cerca de 4 dias), a contagem de mesófilos foi de 8,9 e a de psicrotróficos 7,9Log UFC g-1 , sendo que as amostras apresentaram características sensoriais aceitáveis até o dia 2 de avaliação, tendo sido rejeitadas $(2,8)$ no 5 o dia de estocagem.

A contagem de mesófilos dos filés submetidos à EAM manteve-se estável no primeiro dia $\left(4,6 \mathrm{Log} \mathrm{UFC}^{-1}\right)$, próxima àquela do dia zero $(4,2 \mathrm{Log}$ UFC $\left.\mathrm{g}^{-1}\right)$. As bactérias mesófilas cresceram proporcionalmente com o tempo de estocagem. No entanto, tal evolução apresentou-se mais lenta que a das amostras controle, somente alcançando o limite no 13ํ dia de estocagem. Em relação aos psicrotróficos, apenas foi observado crescimento a partir do 9o dia (2,9Log UFC $\left.\mathrm{g}^{-1}\right)$, ultrapassando o limite somente no 17ํ dia. Isso, provavelmente deveu-se à eficácia do processo de EAM em reduzir a multiplicação bacteriana (MANO et al., 2000), corroborando o estudo de SOCCOL et al. (2005), os quais observaram diminuição do desenvolvimento bacteriano nas amostras embaladas em atmosfera modificada e concluíram que, quando comparado ao grupo controle, a EAM proporcionou melhor conservação dos filés de tilápia, fenômeno também observado em sardinha (LOPES, 2004) e frango (MANTILLA et al., 2009). As amostras submetidas ao tratamento 2 apresentaram cor e aparência geral aceitáveis até o $12^{\circ}$ dia $(5,4)$, obtendo rejeição no $15^{\circ}$ dia $(2,8)$ de estocagem. Dentre os demais tratamentos, os filés do lote T2 foram os que obtiveram significativamente $(\mathrm{P}<0,05)$ menores escores de aceitação, fato que pode ser atribuído à perda de drip, tornando o filé mais pálido e flácido (TEIXEIRA, 2009). A EAM foi eficaz e estendeu a validade comercial em torno de 9 dias e, apesar de ter reduzido significativamente $(\mathrm{P}<0,05)$ a aceitação dos atributos sensoriais, não teve sua aplicabilidade comprometida.

A contagem de mesófilos nas amostras irradiadas foi de 2,2Log UFC g ${ }^{-1}$ no primeiro dia de análise, ou seja, durante a irradiação, houve redução de aproximadamente $50 \%$ da carga microbiana, o que fez com que o limite estabelecido somente fosse ultrapassado no $14^{\circ}$ dia de estocagem. Em relação aos psicrotróficos, houve crescimento a partir do $11^{\circ}$ dia, sendo que o limite somente foi atingido no $18^{\circ}$ dia de armazenamento. Esta redução da carga inicial se deve, principalmente, ao efeito da radiação ionizante sobre o DNA cromossômico, já que lesa os ácidos nucléicos das bactérias contaminantes, acarretando a morte 


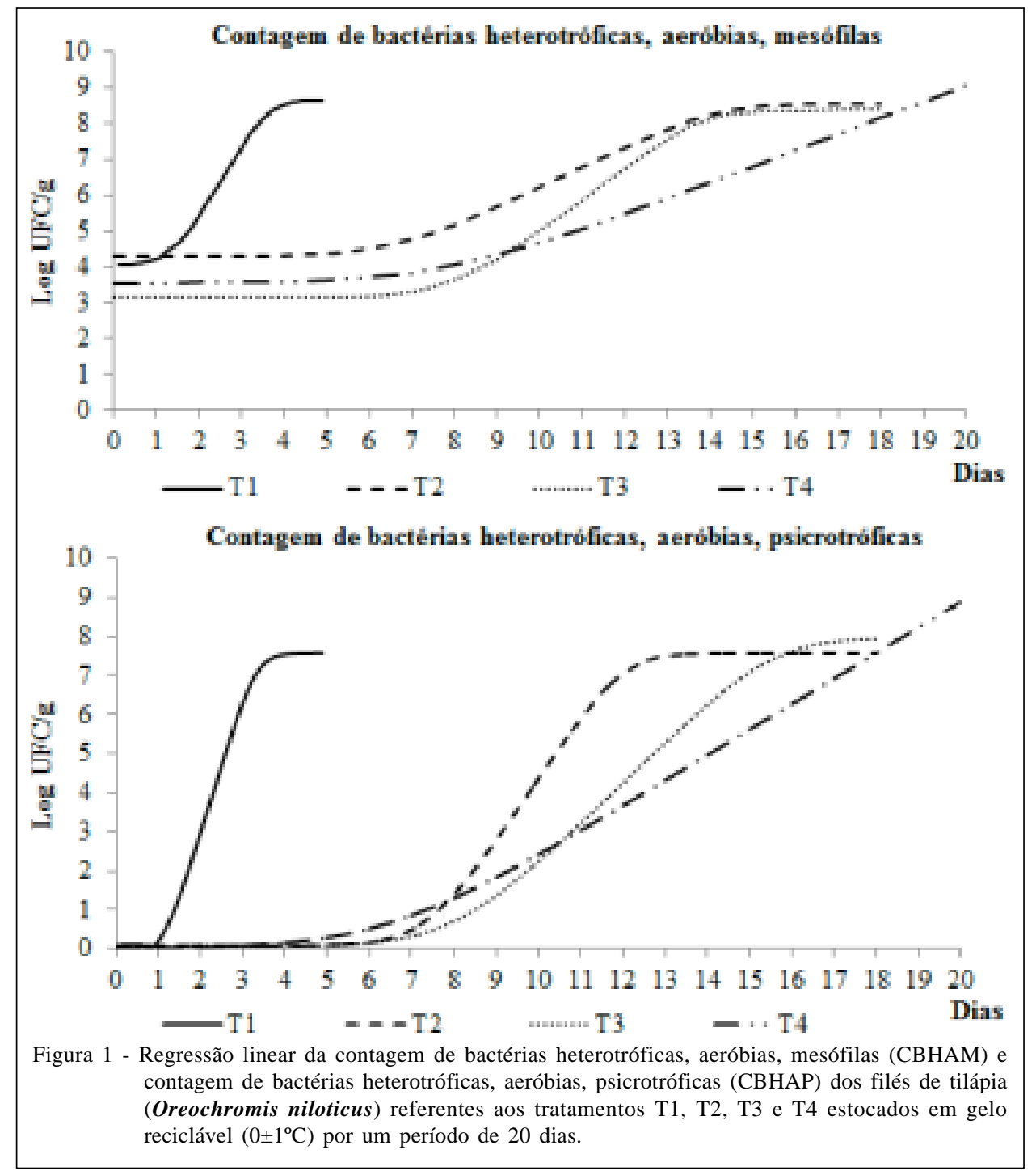

celular(VITAL \& FREIRE, 2008), estendendo a validade comercial dos alimentos. TEIXEIRA (2009) relatou que, durante todo o período de estocagem, amostras irradiadas apresentaram melhores resultados que aqueles de amostras não irradiadas, provocando extensão da validade comercial. SIQUEIRA (2001) e COZZO et al. (2003) também observaram, quando comparado ao grupo controle, maior validade comercial nos filés de tilápia irradiados, fato também contatado em outras matrizes alimentares, como o frango, que, segundo MANTILLA et al. (2009), apresentaram eficácia aumentando em nove dias a validade comercial. A irradiação não interferiu significativamente $(\mathrm{P}<0,05)$ nos atributos cor e aparência geral dos filés no dia zero. Com o aumento do tempo de estocagem, observou-se um decréscimo na sua aceitação, que evoluiu para rejeição no $15^{\circ}$ dia $(4,7)$ de armazenamento, em concordância com os resultados descritos por TEIXEIRA (2009). A validade comercial das amostras tratadas somente com irradiação foi prolongada em 10 dias, o que comprova a boa eficácia deste tratamento no aumento do período de estocagem.

A contagem de mesófilos das amostras submetidas ao grupo T4 revelou, no primeiro dia, uma redução de $25 \%$ na carga microbiana. Embora inferior àquela mensurada nos filés do grupo T3, a multiplicação bacteriana foi menor, sendo o limite somente ultrapassado no 17ํㅡ dia de estocagem, denotando maior eficácia da combinação dos tratamentos em comparação com os demais. O mesmo ocorreu com a contagem de psicrotróficos, que revelou crescimento a partir do dia 11, superando o limite apenas no $20^{\circ}$ dia de estocagem. Isto provavelmente ocorreu devido ao efeito sinérgico resultante da combinação dos processos de conservação utilizados, sem prejuízo significativo $(\mathrm{P}<0,05)$ à aceitação sensorial do produto, 
que foi rejeitado a partir do 19 dia $(4,1)$ de estocagem, conforme os achados de TEIXEIRA (2009).

\section{CONCLUSÃO}

Conclui-se que os filés de tilápia controle apresentaram uma validade comercial de apenas quatro dias. A embalagem em atmosfera modificada e a irradiação foram eficazes no prolongamento da validade comercial dos filés de tilápia, no entanto, a maior extensão foi evidenciada nos filés tratados, que apresentaram bom estado de conservação até 13 dias de estocagem, condição esta obtida com a utilização de ambos os métodos de conservação e, por isso, recomenda-se o uso combinado da embalagem em atmosfera modificada (40\% de $\mathrm{CO}_{2}$ e $60 \%$ de $\mathrm{N}_{2}$ ) e da irradiação (1,5kGy) para a conservação de filés de tilápia do Nilo.

\section{REFERÊNCIAS}

AL-KAHTANI, H.A. et al. Chemical changes after irradiation and post-irradiation storage in Tilapia and Spanish Mackerel. Journal of Food Science, v.61, n.4, p.729-733, 1996. Disponível em: <http://onlinelibrary.wiley.com/doi/10.1111/ j.13652621.1996.tb12191.x/pdf>. Acesso em: 05 maio, 2010. doi: 10.1111/j.1365-2621.1996.tb12191.

APHA. Compendium of methods for the microbiological examination of foods. 4.ed. Washington, 2001. 600p.

BRASIL. Ministério da Agricultura, Pecuária e Abastecimento. Secretaria Nacional de Defesa Agropecuária. Laboratório Nacional de Referência Animal. Métodos analíticos oficiais para controle de produtos de origem animal e seus ingredientes: II - Métodos físicos e químicos. Brasília, 1981. $85 p$.

BRASIL. Ministério da Agricultura, Pecuária e Abastecimento. Secretaria de Defesa Agropecuária. Instrução Normativa no ${ }^{\circ} 62$ de 26 de Agosto de 2003. Métodos analíticos oficiais para análises microbiológicas para controle de produtos de origem animal e água. Brasília, 2003. p.14-18.

BRASIL. Ministério da Agricultura e Reforma Agrária. Regulamento da Inspeção Industrial e Sanitária de Produtos de Origem Animal. Brasília, 2008. 154p.

BRASIL. Ministério da Pesca e Aquicultura. Boletim Estatístico da Pesca e Aquicultura, 2010. 101p.

CARBONERA, N. et al. Análise de perigos e pontos críticos de controle no processamento de filés congelados de tilápia (Oreochromis niloticus). Disponível em: <http:// $200.169 .53 .89 /$ download/CD\%20 congressos/2006/ CRICTE\%202006/trabalhos/657672-ega-01-09-62134.pdf>. Acesso em: 02 set. 2011.

COZZO, A.Z. et al. Effects of irradiation and refrigeration on the nutrients and shelf-life of tilapia. Journal of Aquatic Food Product Technology, v.12, n.3, p.85-102, 2003. Disponível em: <http://www.tandfonline.com/doi/abs/10.1300/ J030v12n01_06>. Acesso em: 18 jun. 2010. doi: 10.1300/ J030v12n01_06.
FRANCO, B.D.G.M.; LANDGRAF, M. Microbiologia dos alimentos. São Paulo: Atheneu, 1996. 182p.

LOPES, M.M. et al. Efeito da embalagem em atmosfera modificada sobre a conservação de sardinhas (Sardinella brasiliensis). Revista Portuguesa de Ciências Veterinárias, v.99, n.552, p.207-210, 2004. Disponível em: <http://www.fmv.utl.pt/s pcv/PDF/pdf12_2004/ 552_207_210.pdf>. Acesso em: 15 jun. 2010. doi: 552207210.

MANO, S.B. et al. Growth/survival of natural flora and Aeromonas hydrophila on refrigerated uncooked pork and turkey packaged in modified atmospheres. Food Microbiology, v.17, n.6, p.657-669, 2000. Disponível em: <http:// www.idealibrary.com>. Acesso em: 15 jun. 2010. doi: 10.1006/ fmic. 2000.0358.

MANTILLA, S.P.S. et al. Bactérias deteriorantes em filés de frango embalados em ar, vácuo e irradiados: parâmetros bacteriológicos de desenvolvimento e prazo comercial. Pesquisa Agropecuária Tropical, v.39, n.4, p.271-277, 2009. Disponível em: <http://www.sumarios.org/sites/default/files/pdfs/ 45137_5519.PDF>. Acesso em: 16 set. 2011. doi: 451375519.

MÁRSICO, E.T. et al. Avaliação da qualidade de sushis e sashimis comercializados em shoppings centers. Higiene Alimentar, v.20, p.63-65, 2006. (Impresso).

MASNIYOM, P. et al. Shelf-life extension of refrigerated sea bass slices under modified atmosphere packaging. Journal of the Science of Food and Agriculture, v.82, n.8, p.873-880, 2002. Disponível em: <http://onlinelibrary.wiley.com/doi/ 10.1002/jsfa.1108/pdf $>$. Acesso em: 20 maio, 2010. doi: $10.1002 /$ jsfa. 1108 .

OGAWA, M.; MAIA, E. Manual de pesca - Ciência e tecnologia de pescados. São Paulo: Varela, 1999. 458p.

SIQUEIRA, A.A.Z.C. Efeitos da irradiação e refrigeração na qualidade e no valor nutritivo da Tilápia. 2001. $154 \mathrm{f}$. Dissertação (Mestrado em Ciência e Tecnologia de Alimentos) - Escola Superior de Agricultura “Luiz de Queiroz”, Universidade de São Paulo, Piracicaba, SP.

SOCCOL, M.C.H. et al. Effects of modified atmosphere and vacuum on the shelf life of tilapia fillets. Brasilian Journal of Food Technology, v.8, n.1, p.7-15, 2005. Disponível em: <http://www.ital.sp.gov.br/bj_old/brazilianjournal/free/ p05181.pdf $>$. Acesso em: 23 jun. 2010. doi: p05181.

TARLADGIS, B.G. et al. A distillation method for the quantitative determination of malonaldehyde in rancid foods. Journal of the American Oil Chemists' Society, v.37, p.44-48, 1960. Disponível em: <http://www.springerlink.com/ content/901px1g3vp7hj263/>. Acesso em: 15 maio, 2010. doi: $10.1007 / \mathrm{BF} 02630824$

TEIXEIRA, C.E. Avaliação do efeito combinado dos processos de irradiação e atmosfera modificada na qualidade bacteriológica, físico-química e sensorial do filé de tilápia (Oreochromis niloticus) resfriado. 2009. $119 f$. Tese (Doutorado em Higiene Veterinária) - Faculdade de Veterinária, Universidade Federal Fluminense, Niterói, RJ.

VITAL, H.C.; FREIRE, M. Jr. A irradiação de alimentos. In: ROSENTHAL, A. Tecnologia de alimentos e inovação: tendências e perspectivas. Brasília: Embrapa Informação Tecnológica, 2008. Cap.11, p.1-193. 